\title{
Congenital Heart Diseases Detected by Prenatal Fetal Echocardiography and Associated Extracardiac Anomalies
}

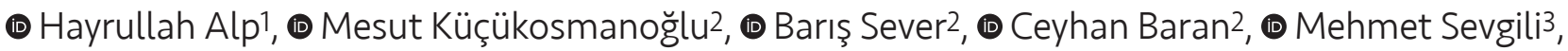 \\ (1) Ahmet Midhat Elmacl ${ }^{4}$, (1) Esma Keleş Alp 5 \\ 1Dr. Ali Kemal Belviranlı Obstetrics And Children Hospital, Department of Pediatric Cardiology, Konya, Turkey \\ 2Dr. Ali Kemal Belviranlı Obstetrics and Children Hospital, Department of Obstetrics and Gynecology, Konya, Turkey \\ ${ }^{3}$ Dr. Ali Kemal Belviranlı Obstetrics and Children Hospital, Department of Radiology, Konya, Turkey \\ ${ }^{4}$ Dr. Ali Kemal Belviranlı Obstetrics and Children Hospital, Department of Pediatric Nephrology, Konya, Turkey \\ ${ }^{5}$ Dr. Ali Kemal Belviranlı Obstetrics and Children Hospital, Department of Pediatrics, Konya, Turkey
}

\begin{abstract}
Aim: The aim of this study is to determine the relationship between extracardiac abnormalities and congenital heart diseases in fetuses that were referred for fetal echocardiography due to a variety of reasons.

Materials and Methods: A total of 1,158 pregnant woman whose fetal echocardiograms and detailed fetal anomaly scanning were performed between June 2017 and July 2018 were included in this study. The documents of the pregnant women were reviewed retrospectively. Those fetuses who were determined to have various organ anomalies and congenital heart defects were recorded.

Results: While 664 pregnant women were in the low-risk group, 494 pregnant women were in the high-risk group in the study. Congenital heart defects were detected in a total of 38 pregnant women (3.28\%). The prevalence of all gastrointestinal system, urinary system and central nervous system anomalies were $5.35 \%, 3.79 \%$ and $6.73 \%$, respectively. Interventricular septum, aorta, pulmonary and tricuspid valves associated with congenital heart diseases were found to be mostly related with these organ anomalies.

Conclusion: Gastrointestinal system and central nervous system anomalies were found to be mostly associated with congenital heart diseases. Also, the interventricular septum, aortic, pulmonary and tricuspid valves' anomalies were the most frequently detected congenital heart diseases in these situations.
\end{abstract}

Keywords: Fetal echocardiography, fetal anomaly scanning, congenital heart diseases, extracardiac anomalies

\section{Introduction}

Congenital heart diseases are common in neonates, complicating approximately $1 \%$ of live births (1). At the same time, the risk increases with fetal abortion and peripartum fetal death. Additionally, congenital heart diseases are the most common cause of death due to prenatal congenital anomalies (2). Therefore, the early detection of congenital heart diseases allows for reliable peripartum treatment strategies (3). Also, the detection of congenital heart diseases in the prenatal period has been demonstrated to improve survival after surgery 
and neurological outcomes in neonates (4). The survey of congenital heart diseases in the perinatal period depends on the associated extra cardiac organ anomalies, chromosomal anomalies, legal differences in each of the countries and the families' desire for the baby (5). Today, fetal echocardiography is increasingly used in the prenatal diagnosis of congenital heart diseases. Pregnancies with fetal, maternal or hereditary reasons for fetal echocardiography are considered to be high-risk groups $(6,7)$. Additionally, suspicion of fetal congenital heart disease in the second trimester or the detection of any anomaly in extracardiac organs are the other indications for fetal echocardiography (8). In recent years, there have been reports that the diagnostic sensitivity of fetal echocardiography has increased by up to 78-98\% (9-11).

Extra cardiac anomalies are associated with congenital heart diseases in one fifth of cases, and there is also a high association with aneuploidy on prenatal testing in up to one quarter of cases (12). Currently, there are well-defined chromosomal anomalies such as trisomy 21 associated with congenital heart diseases like atrioventricular septal defect. However, there are limited studies on the association of congenital heart diseases and extracardiac organ anomalies (13-17). The aim of this study is to determine the risk groups in those pregnancies who were sent for fetal echocardiography and to identify the associations between congenital heart diseases and extra cardiac organ anomalies.

\section{Materials and Methods}

\section{Study Population}

This retrospective study was performed between June 2017 and July 2018 and 1,158 pregnant women who were in the $18^{\text {th }}$ to $22^{\text {nd }}$ week of gestation were included in the study. The patients in our study consisted of pregnant women referred by obstetricians, having a previous child or family history of cardiac anomaly and those who were self-referral. All the data of these pregnant women were analyzed in detail for pregnancy history, reasons for referral to our clinic, any drug usage, presence of family history, number and characteristics of previous pregnancies, presence of chromosomal or fetal anomalies and congenital or acquired heart diseases in the family. Also, ultrasonographic fetal anomaly scanning results including any extra cardiac organ anomaly were recorded. The pregnancies were grouped as either high-risk or low-risk pregnancies and compared in terms of congenital heart diseases and extra cardiac organ anomalies.

\section{Fetal Echocardiography}

Fetal echocardiography was performed with Philips Affiniti 50 (Philips Healthcare, Andover, Netherlands) by the same observer and an echocardiographic scanner with 2.5-5 $\mathrm{MHz}$ transducers was used. The fetal examination included the standard techniques to evaluate the position and axis of the heart and for scanning plans and conventional Doppler and M-mode measurements (8-10). The structural disorders of the heart were evaluated by a two-dimensional ultrasound imaging technique and the rhythm and dimensions of the heart were evaluated by the M-mode technique. Echocardiography procedure was repeated several times on those pregnant women who had unclear ultrasound imaging, dysrhythmia, fetuses with congenital heart diseases or extra cardiac organ anomalies and those with poly-pregnancies. Also, prenatal counseling was provided for chromosome anomalies in patients with congenital heart disease detected by fetal echocardiography.

\section{Perinatal Follow-up and Fetal Anomaly Scanning}

Detailed fetal ultrasonography was performed on all of the pregnant women who were included in the study between the $18^{\text {th }}$ and $22^{\text {nd }}$ weeks of gestation. Fetal anomaly scanning was performed by the same radiologist and obstetricians with an ultrasonography device (Philips Affiniti 50, Philips Healthcare, Andover, Netherlands) using 2.5-5 $\mathrm{MHz}$ transducers and extra cardiac organ anomalies were recorded in detail $(12,13)$. Amniocentesis, chorionic villous sampling or cordocentesis was performed for the detection of chromosomal anomalies according to the gestational week in appropriate cases. Also, the ultrasonography procedure was repeated several times on those pregnant women who had unclear ultrasound imaging, dysrhythmia, fetuses with congenital heart diseases or extra cardiac organ anomalies and those with poly-pregnancies.

\section{Statistical Analyses}

All statistical analyses were performed using SPSS for Windows Version 17.0 software (Chicago, IL, USA). The prevalence of congenital heart diseases in low-risk and highrisk pregnancies was compared using the chi-square test. Quantitative variables are expressed as mean \pm standard deviation, and qualitative variables are given as frequency and percentage. Statistical significance was inferred at $\mathrm{p}<0.05$.

\section{Results}

A total of 1,158 pregnant women on whom fetal echocardiography was performed were included in the study. 
The pregnancies were classified as low-risk and high-risk groups according to criteria during referrals (Table I). In this way, 664 (57.34\%) pregnant women were classified as the low-risk group while 494 (42.66\%) pregnant were classified as the high-risk group. In the low-risk group, the largest group were seen to be self-referral (27.73\%). However, fetal organ anomalies $(14.16 \%)$, maternal diabetes $(11.83 \%)$, and history of familial congenital heart diseases $(1.81 \%)$ were the most common reasons for referral in the high-risk group.

The mean ages were $26.65 \pm 8.52$ and $27.21 \pm 12.45$ years in the low-risk and high-risk groups, respectively and no

Table I. Distribution of pregnant women according to low-risk and high-risk factors

\begin{tabular}{|c|c|c|}
\hline Risk groups and factors & n (1.158) & $\%$ \\
\hline \multicolumn{3}{|l|}{ Low-risk } \\
\hline $\begin{array}{l}\text { Suspicion of CHD during } 2^{\text {nd }} \text { trimester } \\
\text { ultrasound }\end{array}$ & 283 & 24.43 \\
\hline Self-referral & 321 & 27.73 \\
\hline $\begin{array}{l}\text { Lack of good image of the fetal heart by } \\
\text { ultrasound }\end{array}$ & 60 & 5.18 \\
\hline Total & 664 & 57.34 \\
\hline \multicolumn{3}{|l|}{ High-risk } \\
\hline \multicolumn{3}{|l|}{ Maternal factors } \\
\hline Maternal diabetes & 137 & 11.83 \\
\hline Maternal use of medicine & 21 & 1.81 \\
\hline Advanced maternal age & 35 & 3.02 \\
\hline Maternal CHD & 5 & 0.43 \\
\hline Maternal rheumatologic diseases & 3 & 0.25 \\
\hline Maternal TORCH diseases & 0 & 0 \\
\hline \multicolumn{3}{|l|}{ Fetal factors } \\
\hline Dysrhythmia & 11 & 0.94 \\
\hline Polyhydramniosis, oligohydramniosis & 35 & 3.02 \\
\hline Immune/non immune hydrops & 3 & 0.25 \\
\hline Fetal extracardiac anomaly & 164 & 14.16 \\
\hline Chromosomal anomaly & 12 & 1.03 \\
\hline Increased nuchal translucency & 13 & 1.12 \\
\hline \multicolumn{3}{|l|}{ Hereditary factors } \\
\hline Previous child or fetus with CHD & 15 & 1.29 \\
\hline $\begin{array}{l}\text { Previous child or fetus with extracardiac } \\
\text { anomaly }\end{array}$ & 19 & 1.64 \\
\hline Familial CHD (excluding parents and siblings) & 21 & 1.81 \\
\hline Total & 494 & 42.66 \\
\hline
\end{tabular}

CHD: Congenital heart diseases, TORCH: Toxoplasmosis, rubella, cytomegalovirus, herpes simplex virus statistically significant difference was found between the two groups $(p>0.05)$ (Table II). The mean gestational week was $21.23 \pm 1.54$ and $21.81 \pm 2.09$ weeks in the low-risk and high-risk groups, respectively. Also, no statistical difference was detected for gestational weeks between the two groups $(p>0.05)$. Primiparas were in the majority in both groups. Additionally, 21 and 19 pregnancies were for twins in the low-risk and high-risk groups, respectively.

In the low risk group; ventricular septal defect, atrioventricular septal defect, and hypoplastic left heart were detected in 5 cases $(0.75 \%), 1$ case $(0.15 \%)$ and 1 case $(0.15 \%)$, respectively. On the other hand, in the high risk group; ventricular septal defect atrioventricular septal defect was detected in 12 cases (2.42\%), Atrioventricular septal defect in 5 cases (1.01\%), aortic stenosis in 2 cases $(0.40 \%)$, double outlet right ventricle in 2 cases $(0.40 \%)$, pulmonary atresia/hypoplasia in 4 cases $(0.81 \%)$, hypoplastic left heart syndrome in 3 cases $(0.61 \%)$, aortic coarctation/ aortic arch hypoplasia in 1 case $(0.20 \%)$, Ebstein anomaly in 1 case $(0.20 \%)$ and tricuspid atresia in 1 case $(0.20 \%)$ (Table III). In this way, the prevalence of congenital heart diseases in our series was found to be $1.05 \%$ and $6.25 \%$ in the low-risk and high-risk pregnancies respectively while the overall prevalence was $3.28 \%$. Amniocentesis samples were performed on 25 pregnant women in the high-risk group and 5 of them had chromosomal anomalies (trisomy 21).

A complete atrioventricular block was detected in two pregnancies in the high-risk group. Also, one of them had mixed connective tissue disease while the other had no diseases rheumatologically and the fetal arrhythmia turned into sinus rhythm in this pregnancy. Additionally, premature atrial beats and supraventricular tachycardia were detected in 8 and 1 pregnant women in the high-risk group and lowrisk groups, respectively.

Fetal anomaly scanning with ultrasonography revealed; esophagus atresia in 3 cases, duodenal atresia in 2 cases,

Table II. The demographic data of pregnant women

\begin{tabular}{|l|l|l|l|}
\hline & $\begin{array}{l}\text { Low-risk } \\
(\mathbf{n = 6 6 4 )}\end{array}$ & $\begin{array}{l}\text { High-risk } \\
(\mathbf{n = 4 9 4 )}\end{array}$ & p value \\
\hline Age (years) & $26.65 \pm 8.52$ & $27.21 \pm 12.45$ & $>0.05$ \\
\hline $\begin{array}{l}\text { Gestational week } \\
\text { (weeks) }\end{array}$ & $21.23 \pm 1.54$ & $21.81 \pm 2.09$ & $>0.05$ \\
\hline Primipara (n/\%) & $434 / 65.36$ & $298 / 60.32$ & $>0.05^{*}$ \\
\hline Multipara (n/\%) & $209 / 31.48$ & $177 / 35.83$ & $>0.05^{*}$ \\
\hline $\begin{array}{l}\text { Multiple pregnancy } \\
\text { (n/\%) }\end{array}$ & $21 / 3.16$ & $19 / 3.84$ & $>0.05^{*}$ \\
\hline
\end{tabular}

*Student t-test 
fetal echogenic bowel in 57 cases, dilatation of the urinary system in 34 cases, renal agenesis in 10 cases and intracranial ventricle dilatation (hydrocephalus) in 78 cases (15.88\%). The prevalence of all gastrointestinal system, urinary system and central nervous system anomalies were 5.35\%, 3.79\% and $6.73 \%$, respectively. The associated congenital heart diseases which were detected in these pregnant women are given in Table IV. Ventricular septal defect and aortic coarctation/ aortic arch hypoplasia were detected in two of the esophageal atresia fetuses (33.33\%). Additionally, atrioventricular septal defect was determined in one of the fetuses with duodenal atresia (50\%). Also, ventricular septal defect was

Table III. Distribution of congenital heart diseases according to risk groups

\begin{tabular}{|l|l|l|}
\hline Congenital heart disease & $\begin{array}{l}\text { Low-risk } \\
\text { (n=664) } \\
\text { (n/\%) }\end{array}$ & $\begin{array}{l}\text { High-risk } \\
\text { (n=494) } \\
\text { (n/\%) }\end{array}$ \\
\hline Ventricular septal defect & $5 / 0.75$ & $12 / 2.42$ \\
\hline Atrioventricular septal defect & $1 / 0.15$ & $5 / 1.01$ \\
\hline Aortic stenosis & $0 / 0$ & $2 / 0.40$ \\
\hline Double outlet right ventricle & $0 / 0$ & $2 / 0.40$ \\
\hline Pulmonary atresia/hypoplasia & $0 / 0$ & $4 / 0.81$ \\
\hline Hypoplastic left heart syndrome & $1 / 0.15$ & $3 / 0.61$ \\
\hline $\begin{array}{l}\text { Aortic coarctation/aortic arch } \\
\text { hypoplasia }\end{array}$ & $0 / 0$ & $1 / 0.20$ \\
\hline Ebstein anomaly & $0 / 0$ & $1 / 0.20$ \\
\hline Tricuspid atresia & $0 / 0$ & $1 / 0.20$ \\
\hline Total & $7 / 1.05$ & $31 / 6.25$ \\
\hline
\end{tabular}

detected in four, atrioventricular septal defect in one, aortic stenosis in one, hypoplastic left heart syndrome in one and tricuspid atresia in one of the fetuses who had echogenic bowel (14.03\%). Fetal echocardiography of the fetuses with urinary system dilatation revealed ventricular septal defect in three, double outlet right ventricle in one, pulmonary atresia/hypoplasia in one, hypoplastic left heart syndrome in one and Ebstein anomaly in one of the fetuses (20.58\%). Ventricular septal defect and pulmonary atresia/hypolasia were detected in two of the fetuses with renal agenesis (20\%). Additionally, ventricular septal defect was detected in three cases, atrioventricular septal defect in one, double outlet right ventricle in one, pulmonary atresia/hypoplasia in one, hypoplastic left heart syndrome in two and aortic coarctation/ aortic arch hypoplasia in one case of those fetuses with intracranial ventricle dilatation (hydrocephalus) (11.53\%).

Echogenic bowel and dilatation of urinary system anomalies were detected in two of Trizomi 21 fetuses. Among these two fetuses, atrioventricular septal defect was determined in one and ventricular septal defect was determined in the other.

\section{Discussion}

In this study, fetal echocardiography was performed on 1,158 pregnant women and the prevalence of congenital heart diseases was determined to be $3.28 \%$. Complex congenital heart diseases and fetal arrhythmias were also determined in our series. Additionally, these congenital heart diseases were at higher rates in the high-risk group compared to the low-risk pregnancies group.

Table IV. The association between congenital heart diseases and extracardiac anomalies

\begin{tabular}{|c|c|c|c|c|c|c|}
\hline \multirow[b]{2}{*}{ Congenital heart disease } & \multicolumn{6}{|c|}{ Extracardiac anomaly } \\
\hline & $\begin{array}{l}\text { Esophagus } \\
\text { atresia } \\
(n=3)\end{array}$ & $\begin{array}{l}\text { Duodenal } \\
\text { atresia } \\
(n=2)\end{array}$ & $\begin{array}{l}\text { Echogenic } \\
\text { bowel } \\
(n=57)\end{array}$ & $\begin{array}{l}\text { Dilatation of } \\
\text { urinary system } \\
(n=34)\end{array}$ & $\begin{array}{l}\text { Renal agenesis } \\
(n=10)\end{array}$ & $\begin{array}{l}\text { Intracranial } \\
\text { ventricle } \\
\text { dilatation } \\
(n=78)\end{array}$ \\
\hline Ventricular septal defect & 1 & & 4 & 3 & 1 & 3 \\
\hline Atrioventricular septal defect & & 1 & 1 & & & 1 \\
\hline Aortic stenosis & & & 1 & & & \\
\hline Double outlet right ventricle & & & & 1 & & 1 \\
\hline Pulmonary atresia/hypoplasia & & & & 1 & 1 & 1 \\
\hline Hypoplastic left heart syndrome & & & 1 & 1 & & 2 \\
\hline Aortic coarctation/aortic arch hypoplasia & 1 & & & & & 1 \\
\hline Ebstein anomaly & & & & 1 & & \\
\hline Tricuspid atresia & & & 1 & & & \\
\hline Total (\%) & $1(33.33)$ & $1(50)$ & $8(14.03)$ & $7(20.58)$ & $2(20)$ & 9 (11.53) \\
\hline
\end{tabular}


Nowadays, the frequency of fetal anomaly scanning with ultrasonography is increasing and the most common referral indication for fetal echocardiography that has the greatest positive yield of fetal congenital heart diseases is that of abnormal fetal anomaly scanning (13). Similarly, in our study, fetal anomaly was found to be the major indication of fetal echocardiography in the high-risk pregnancies group (14.16\%). Also, other reasons were less frequent indications for fetal echocardiography in this group. Therefore, this finding suggests that performing fetal echocardiography during the fetal anomaly scanning is important in detecting congenital heart diseases. Our study revealed that the most common associated organ anomalies to congenital heart diseases were gastrointestinal (5.35\%) and central nervous system (6.73\%) anomalies. Similarly, in a comprehensive study of 1,262 pregnancies by Mone et al. (13), congenital heart diseases were reported to be associated more commonly with gastrointestinal (21.7\%) and neurological system (28.3\%) anomalies. In this context, similar studies have reported the existence of compatible results with the data in our study (14-16). However, Egbe et al. (17) reported that congenital heart diseases were more commonly associated with genitourinary and pulmonary system anomalies and these congenital heart diseases were also more commonly associated with cardiac septum, pulmonary, tricuspid and aortic valves. In our study, it was shown that congenital heart diseases including interventricular septum, tricuspid and aortic valve anomalies were more commonly associated with gastrointestinal system anomalies. On the other hand, our study revealed that congenital heart diseases including interventricular septum, pulmonary and aortic valve anomalies were found to be more commonly associated with central nervous system anomalies. As in the study of Egbe et al. (17), in our study, we reported that congenital heart diseases including cardiac septum, pulmonary and tricuspid valve anomalies were most commonly associated with genitourinary system anomalies.

Various chromosomal anomalies were also detected in our study. However, this number is limited and amniocentesis was not performed for all of the indicated gestations. Therefore, they could not be considered as a separate group. In these gestations, echogenic bowel and dilatation of urinary system anomalies were detected with atrioventricular and ventricular septal defects of congenital heart diseases.

Congenital heart disease is the leading cause of mortality in the neonatal period. Also, the presence of chromosomal or extra cardiac organ anomalies increases this mortality and affects the prognosis with treatment (15). Nowadays, the early detection of fetal organ anomalies with various ultrasonography techniques is increasing in experienced hands. Therefore, this situation may lead to early diagnosis, appropriate treatment and good prognosis.

\section{Conclusion}

In our study, the relationship between congenital heart diseases and extra cardiac organ anomalies indicates the importance of fetal echocardiography and detailed fetal anomaly scanning. Additionally, gastrointestinal and central nervous system anomalies are more frequently associated with congenital heart diseases, and interventricular septum, aortic, pulmonary and tricuspid valve anomalies are the most common congenital heart diseases detected in these conditions.

\section{Ethics}

Ethics Committee Approval: Retrospective study.

Informed Consent: Consent form was filled out by all participants.

Peer-review: Externally and internally peer-reviewed.

\section{Authorship Contributions}

Concept: H.A., M.K., B.S., C.B., Design: H.A., A.M.E., E.K.A., Fetal Echocardiography: H.A., Ultrasonography: M.K., B.S., C.B., M.S.. Data Collection or Processing: H.A., A.M.E., E.K.A., Analysis or Interpretation: M.K., B.S., C.B., M.S., Literature Search: H.A., M.S., Writing: H.A.

Conflict of Interest: No conflict of interest was declared by the authors.

Financial Disclosure: This research received no specific grant from any funding agency, commercial or not-forprofit sectors.

\section{References}

1. Ailes EC, Gilboa SM, Riehle-Colarusso T, et al. Prenatal diagnosis of nonsyndromic congenital heart defects. Prenat Diagn 2014;34:214-22.

2. Ferencz C, Rubin JD, McCarter RJ, et al. Congenital heart disease: prevalence at live birth. The Baltimore-Washington Infant Study. Am J Epidemiol 1985;121:31-6.

3. Simpson LL. Screening for congenital heart disease. Obstet Gynecol Clin North Am 2004;31:51-9.

4. Slansky MS, Berman DP, Pruetz JD, et al. Prenatal screening for major congenital heart disease. Superiority of outflow tracts over the 4-chamber view. J Ultrasound Med 2009;28:889-99.

5. Abuhamad A, Chaoui R. A practical guide for fetal echocardiography. 2nd ed. Philadelphia: Lippincott Williams and Wilkins; 2010.

6. Perri T, Cohen-Sacher B, Hod M, Berant M, Meizner I, Bar J. Risk factors for cardiac malformations detected by fetal 
echocardiography in a tertiary center. I Matern Fetal Neonatal Med 2005;17:123-8.

7. Hartge DR, Weichert I, Krapp M, Germer U, Gembruch U, Axt-Fliedner R. Results of early foetal echocardiography and cumulative detection rate of congenital heart disease. Cardiol Young 2011;21:505-17.

8. Wright L, Stauffer N, Samai C, Oster M. Who should be referred? An evaluation of referral indications for fetal echocardiography in the detection of structural congenital heart disease. Pediatr Cardiol 2014;35:928-33.

9. Azcárate $M J M$, Jiménez $M Q$. The technique of fetal echocardiography, with its indications and results in a selected population. Cardiol Young 1991;1:141-8.

10. Özkutlu S, Ayabakan C, Karagöz T, et al. Prenatal echocardiographic diagnosis of congenital heart disease: comparison of past and current results. Turk I Pediatr 2005; $47: 232-8$

11. Özkutlu S, Bostan OM, Deren O, et al. Prenatal echocardiographic diagnosis of cardiac right/left axis and malpositions according to standardized Cordes technique. Anadolu Kardiyol Derg 2011;11:131-6.
12. Clur SA, Van Brussel PM, Mathijssen IB, Pajkrt E, Ottenkamp I, Bilardo CM. Audit of 10 years of referrals for fetal echocardiography. Prenat Diagn 2011;31:1134-40.

13. Mone F, Walsh C, Mulcahy C, et al. Prenatal detection of structural cardiac defects and presence of associated anomalies: a retrospective observational study of 1262 fetal echocardiograms. Prenat Diagn 2015;35:577-82.

14. Stoll C, Clementi M, Euroscan study group. Prenatal diagnosis of dysmorphic syndromes by routine fetal ultrasound examination across Europe. Ultrasound Obstet Gynecol 2003;21:543-51.

15. Pablo Marantz P, Sáenz Tejeira MM, Peña G, Segovia A, Fustiñana C. Fetal and neonatal mortality in patients with isolated congenital heart diseases and heart conditions associated with extracardiac abnormalities. Arch Argent Pediatr 2013;111:418-22.

16. Song MS, Hu A, Dyamenahalli U, et al. Extracardiac lesions and chromosomal abnormalities associated with major fetal heart defects: comparison of intrauterine, postnatal and postmortem diagnoses. Ultrasound Obstet Gynecol 2009;33:552-9.

17. Egbe A, Lee $S$, Ho D, Uppu S, Srivastava S. Prevalence of congenital anomalies in newborns with congenital heart disease diagnosis. Ann Pediatr Cardiol 2014;7:86-91. 